\title{
Child injury prevention: a survey of local authorities and health boards.
}

\author{
An article produced for International Journal of Health Promotion and \\ Education by
}

\author{
Anna Chisholm ${ }^{1}$ \\ Michael C. Watson BSc (Hons), PGCE, MA(Ed), MPH, PHD ${ }^{1}$ \\ Sarah J. Jones BSc (Hons), MA, PhD ${ }^{2}$ \\ and Denise Kendrick BM, DM, FRCGP, MFPH, $\mathrm{MSc}^{3}$
}

1. Faculty of Medicine and Health Sciences, University of Nottingham, Nottingham, UK

2. Public Health Wales/Cardiff University, Cardiff, UK

3. School of Medicine, Division of Primary Care, Floor 13, Tower Building, University Park, Nottingham, UK

Manuscript word count $=3024$

No. of tables $=4$

Corresponding author: Dr Michael Craig Watson, Faculty of Medicine and Health Sciences, School of Health Sciences, University of Nottingham, Queen's Medical Centre, Nottingham NG7 2HA, UK.

Tel: 01158230760

E-mail: michael.watson@nottingham.ac.uk 


\begin{abstract}
Aims: Unintentional home injuries are a significant global public health issue and are a major cause of mortality and morbidity. Within each country, injuries disproportionately affect children from low income families. Recent guidance issued in the UK recommends actions to be taken by local authorities to reduce injury rates and inequalities. This study aimed to describe and quantify child home injury prevention activities of local authorities (LAs) in England and health boards (HBs) in Wales.
\end{abstract}

Methods: A questionnaire was sent to Directors of Public Health (DsPH) in all 153 uppertier LAs in England and 7 HBs in Wales. The questionnaire covered the five broad areas recommended for injury prevention activities by NICE guidelines.

Results: A response rate of 58\% was achieved. NICE guidance $(75 \%)$ and Public Health England guidance $(57 \%)$ were most commonly used to support child injury prevention decision making. Half $(50 \%)$ of respondents had a child injury prevention alliance in their area. One fifth (19\%) reported that their area had a written child injury prevention strategy. Fewer than half of responders provided training to practitioners about child unintentional injury prevention $(43 \%)$, home safety assessments $(43 \%)$ or an equipment scheme (43\%). Of the $43 \%$ of areas with equipment schemes, most (59\%) were small scale, supplying up to 200 families per year with equipment.

Conclusions: Although some $\mathrm{LAs} / \mathrm{HBs}$ show implementation of recent guidance on preventing home injuries in childhood, most do not. LAs/HBs are likely to need support to implement guidance in order that child injury rates and inequalities can be reduced.

Keywords: local authorities, health boards, injury prevention, national survey, England and Wales 


\section{INTRODUCTION}

Child unintentional injuries are a significant global public health issue and a major cause of mortality and morbidity (Peden et al. 2008). The burden of these injuries is greatest in low income countries, however within each country, injuries disproportionately affect children from low income families (Peden et al. 2008; Edwards et al. 2006; Lyons et al. 2003; Hippisley-Cox et al. 2002). In deprived areas important risk factors are unsafe homes, play and road environments (Laflamme et al. 2009). Under the age of 5 years, most unintentional injuries occur in the home (British Medical Association 2001; Public Health England 2014).

Global interest in addressing the injury burden has identified a range of successful and promising interventions (Hemenway 2009; Watson and Errington 2016). The World and European reports on child injury prevention: highlight injury as a significant public health issue; assemble recent research evidence; and importantly identify effective approaches for tackling the main causes of injury-related mortality and morbidity (Peden et al. 2008; Sethi et al. 2008). These reports stress the need for intersectoral action across government, civil society, and the private sector. They also recommended using a combination of approaches including: education; environmental modification; and legislation.

More recently, an updated Cochrane systematic review found that home safety interventions provided as one-to-one, face-to-face education, especially with the provision of safety equipment, are effective in increasing a range of safety practices (Kendrick et al. 2012). Families who received home safety interventions were more likely to have a safe hot tap water temperature, a working smoke alarm, a fire escape plan, fitted stair gates, socket covers on unused sockets, syrup of ipecac (used to make a child vomit after swallowing poison), poison control centre numbers accessible, and to store medicines and cleaning products out of reach of children. They also found that safety education was equally effective in the families whose children were at greater risk of injury.

In England, the policy response to child injuries has suffered from a lack of national coordination, but now the National Institute for Health and Care Excellence (NICE) and, more recently, Public Health England (PHE) have produced clear guidance (Public Health England 2014; National Institute for Health and Clinical Excellence 2010a, 2013). Public Health England's home safety document specifically focusses on pre-school children and highlights a need for workforce training and leadership to progress action on injury (Public Health 
England 2014). It also recommends that prevention for children aged under 5 years should focus on injury types: choking/suffocation/strangulation; falls; poisonings; burns/scalds; and drowning. The guidance is targeted at a wide range of groups and organisations including health services, health and wellbeing boards and local authorities.

In Wales, a Children in Wales report recommended improvements to the national and local injury prevention structure through leadership, co-ordination and partnership working, and implementation of home safety equipment schemes for vulnerable families initiated through multi-sectoral work and practitioner training (Children in Wales 2008).

Health boards (HBs) in Wales and local authorities (LAs) in England are responsible for promoting the health of the populations they serve. The Health and Social Care Act 2012 moved public health services in England from the NHS into LAs (Department of Health 2012), the aim being to allow the wider determinants of health to be tackled more effectively by bringing together services such as: social care, housing, environmental health, leisure and transport; promoting closer working between LAs and the NHS.

Although NICE and PHE have provided recommendations and guidance to help LAs/HBs to prevent home injuries in childhood, there is no recent evidence on the extent to which they are acting on this guidance. The aim of this study was to determine how LAs/HBs are participating in preventing unintentional injuries in the home in children under the age of 5 .

\section{METHODS}

Directors of Public Health (DsPH) in all 153 upper tier LAs in England and 7 HBs in Wales were invited to complete an on-line questionnaire developed specifically for this study and reviewed by the Child Accident Prevention Trust (CAPT) and Royal Society for the Prevention of Accidents (RoSPA) to ensure content validity.

The questionnaire covered five broad areas recommended for injury prevention activities in NICE guidelines (National Institute for Health and Clinical Excellence 2010a, 2010b). These areas were:

- Injury prevention co-ordinator details 
- Key documents

- Current activities and funding

- Joint working

- Decision making about commissioning injury prevention.

The question about injury prevention coordinators asked whether LAs/HBs had a designated child injury prevention coordinator or someone who undertook that role alongside other responsibilities. Details of the questionnaire respondent from each LA/HB were also collected.

The pilot questionnaire (29 questions) was tested in 50 LAs with the highest hospital admission rates for injury in children under 5 year olds for 2010-11 (Public Health England 2012). Following the pilot, the questionnaire was reduced to 18 questions, still covering the five broad areas highlighted. Minor adjustments were made to the survey sent to Welsh HBs to account for the different health service structures in Wales.

A number of strategies were used to encourage completion namely: an introductory email containing the logos of the University of Nottingham, RoSPA and CAPT, that also outlined the way in which the results would be used; addressing the invitation to a named individual, usually the Director of Public Health; a follow-up letter, sent two weeks after the email, including a paper copy of the questionnaire, to non-responders; circulating the questionnaire to contacts in local authorities and health boards from which responses had not yet been received; sending a second follow-up letter and questionnaire, two weeks after the first, again by post, to non-responders; finally, a telephone call one week after the second follow-up. The questionnaire was also promoted through public health networks, including the UK Faculty of Public Health and the Association of Directors of Public Health, and on authors and organisational websites. Research has previously shown these techniques to improve response rates (Edwards et al. 2002; McColl et al. 2001; Edwards et al. 2009).

Responses were collated and data were cleaned using MS Excel. Where initial questions were answered "no" or "don't know", but sub-questions were then answered, the initial question was re-coded to "yes". Analysis was then carried out using Stata 13.1 (StataCorp 2013).

Descriptive analyses were carried out, including comparisons of a range of activities undertaken by presence of (a) an injury prevention coordinator, (b) child injury prevention 
strategy and (c) a geographical child injury prevention alliance using chi-squared tests and logistic regression (Hogg 1996; Towner et al. 1998; National Institute for Health and Clinical Excellence 2010a, 2010b). Activities were also compared between LAs and HBs by hospital admission rates for injury amongst 0-4 year olds (Public Health England 2015a) and by deprivation, measured using the index of Multiple Deprivation scores (Public Health England 2015b). Comparisons were completed using t-tests or Mann-Whitney $U$ tests dependent on distributions and by logistic regression with admission rates or deprivation scores as explanatory variables. Where relationships were non-linear, the continuous variable was divided into tertiles to allow for comparisons. Characteristics of responder and non-responder LAs and HBs were compared using t-tests or Mann-Whitney $U$ tests dependent on distributions.

Ethical approval was obtained from the Division of Epidemiology and Public Health Ethics Committee, University of Nottingham. All information obtained was anonymised and aggregated.

\section{RESULTS}

\section{Response rate and respondents' characteristics}

A total of $93(58 \%)$ responses were received from 160 LAs and HBs. LAs and HBs who responded to the survey served larger populations (median population 287,000 vs. 241,000, $\mathrm{z}=-1.94, \mathrm{p}=0.05)$ and had higher hospital admission rates for injury amongst $0-4$ year olds (mean rate $\mathrm{t}=-153.7$ per 10,000 vs. $132.7 ; \mathrm{t}=2.75, \mathrm{p}=0.01$ ) than non-responders, but deprivation levels were similar (mean IMD scores responders 23.7 vs. non-responders 22.3, $\mathrm{t}=-1.04, \mathrm{p}=0.30)$.

\section{Injury prevention co-ordinator}

Thirty-one percent (29/93) stated their LA/HB had a child injury prevention co-ordinator (IPC) or person who undertook that role alongside other responsibilities, with around half of respondents $(16 / 29,55 \%$, ) being the IPC themselves. Additionally, $6 \%(5 / 88)$ stated that there was an IPC in their area who was not employed by the LA/HB.

\section{Injury prevention documents and sources of data}


Most LAs/HBs (65/86, 76\%) who responded, produced a joint strategic needs assessment referring to child unintentional injury prevention (table 1), however few referred to it in their local health and well being strategy $(24 / 84,29 \%)$ or DPH annual report $(27 / 82,33 \%)$.

\section{Insert table 1}

The main sources of data used by LA/HBs to make decisions on child injury prevention activities (Table 2) were the Public Health Outcomes Framework (69/87, 79\%) hospital admissions data (70/90, 78\%) and A\&E attendance data (66/87, 76\%).

\section{Insert table 2}

The main documents used to make decisions about child injury prevention were NICE guidance $(66 / 88,75 \%)$ and PHE guidance $(46 / 81,57 \%)$.

\section{Injury prevention activities}

Only one fifth $(16 / 86,19 \%)$ of respondents reported their LA/HB had a written child injury prevention strategy (Table 3). Less than half of LAs/HBs provided training to practitioners about child unintentional injury prevention (39/91, 43\%), or provided home safety assessments (40/92, 43\%) or an equipment scheme (39/91, 43\%). Practitioners included local authority staff and health service staff.

Of the LAs/HBs with equipment schemes $(n=39)$, most who reported the number of families receiving equipment $(10 / 17,59 \%)$ supplied up to 200 families per year with equipment, usually funded by public health departments. Half (44/88, 50\%) of LAs/HBS had a child injury prevention alliance in their area.

\section{Insert table 3}

\section{Comparison between injury prevention activities}

LAs/HBs that had a child IPC were more likely to provide training to practitioners (odds ratio (OR) 3.99; 95\% confidence intervals (CI),1.57-10.14; table 4), home safety assessments (OR $2.95 ; 95 \%$ CI 1.18 to 7.38 ), an equipment scheme (OR 4.67; 95\% CI 1.80 to12.07) have a child injury prevention strategy (OR 5.20; 95\% CI 1.65 to 16.41 ) and a geographical alliance (OR 3.75; 95\% CI 1.42 to 9.88) compared with those who did not have a IPC. A geographical alliance was defined as a group in LAs/HBs local area which aided injury prevention in the 
home in children under 5 years. Additionally LAs/HBs that had a geographical alliance were more likely to provide child injury prevention training to practitioners (OR 5.20; 95\% CI 2.05 to 13.22 ) and an equipment scheme (OR 3.95; 95\% CI 1.60 to 9.76) compared with those who did not have an alliance. However there was no statistical difference between LA/HBs that had a written child injury prevention strategy and those who did not, with regards to providing training to practitioners, home safety assessments or an equipment scheme and those who had a geographical alliance and those who did not with regards to providing home safety assessments.

Insert table 4

\section{Comparison between hospital admission rates and injury prevention activities}

There were no significant associations between hospital admission rates for injury amongst 0 4 year olds and having an injury prevention coordinator (OR middle tertile of admission rates compared to lowest rates tertile $1.85 ; 95 \%$ CI 0.62 to 5.56; OR highest rates tertile compared to lowest rates tertile $1.18 ; 95 \%$ CI 0.38 to 3.67 ), having an injury prevention strategy (OR for one unit increase in admission rates $1.01 ; 95 \%$ CI 0.99 to 1.02 ), having a geographical alliance (OR for one unit increase in admission rates $1.01 ; 95 \%$ CI 1.00 to 1.02 ), providing training (OR for one unit increase in admission rates $1.01 ; 95 \%$ CI 1.00 to 1.02 ), providing home safety assessments (OR middle tertile of admission rates compared to lowest tertile $0.57 ; 95 \%$ CI 0.19 to 1.71 , OR highest tertile compared to lowest tertile $1.74 ; 95 \%$ CI 0.62 to4.93) or providing a home safety equipment scheme (OR for one unit increase in admission rates $1.00 ; 95 \%$ CI 0.99 to 1.01$)$.

\section{Comparison between IMD scores and injury prevention activities}

The activities investigated were: presence of co-ordinator; having a written strategy; existence of an alliance; provision of training; home safety assessments; and providing a home safety equipment scheme (HBs and the Greater London Authority were not included due to IMD scores being unavailable). There were no significant differences in IMD scores between LAs with activity and those without. The median IMD score was higher in all of the groups with the unintentional injury prevention activity compared to those without. However no differences reached statistical significance and all odds ratios equalled or were very close to one. 


\section{DISCUSSION}

\section{Main findings of this study}

Our study shows substantial variation in child home injury prevention activities in LAs/HBs across England and Wales. Although some LAs/HBs showed implementation of recent guidance, most did not. Only one third of LAs/HBs have an IPC and only half have a child injury prevention alliance. Although child injury prevention appears in Joint Strategic Needs Assessments in over $70 \%$ of $\mathrm{LAs} / \mathrm{HBs}$, the topic appears less commonly in Health and Wellbeing Board Strategies and DPH annual reports. This lack of strategic development is highlighted by only $19 \%$ of LAs/HBs having a child injury prevention strategy. The importance of coordination of child injury prevention work was highlighted, with LAs/HBs with a child IPC, or other similar role, significantly more likely to undertake child home injury prevention activities than those without a coordinator.

\section{Strengths and limitations of this study}

This is the first survey of child home injury prevention in LAs/HBs since the Health and Social Care Act 2012 moved public health services in England from the NHS into Las (Department of Health 2012). In Wales, public health has stayed in the NHS, but this made little difference to the results. The response rate (58\%) was good, especially given the challenging circumstances faced by LA/HB public health departments arising from repeated public health budget cuts. Responders were more likely to come from larger LAs/HBs and with higher child injury hospital admission rates. It is possible that LAs/HBs that were more interested in, more motivated to undertake or more active in child injury prevention were more likely to respond, in which case our survey may have overestimated injury prevention activity. As with any survey, social desirability bias may have occurred, with respondents replying in a way that they considered would be viewed favourably. If this has occurred, it would tend to overestimate injury prevention activity. As we found low levels of injury prevention activity, any over-estimation of activity strengthens our conclusions that greater prioritisation of child home injury prevention is needed.

Our comparisons of injury prevention activity by presence of co-ordinators, alliances, child injury prevention strategies and hospital admission rates may have been underpowered to detect anything but large differences due to small numbers in some groups. The crosssectional nature of these comparisons means we are unable to draw conclusions about the 
temporal nature of associations. In addition other unmeasured factors, such as public health budgets, may explain some of the associations we found e.g. the association between having an injury prevention coordinator and a home safety equipment scheme, as both require funding.

\section{Comparisons with existing literature}

There are no other published surveys of LA/HB child home injury prevention activity with which to compare our findings. However, our findings resonate with those from previous national surveys of health authorities, primary care groups and more recently of children's centres. A survey of Health Authorities in 2001 found only one third had an IPC; almost identical to our findings (Watson and White 2001). This suggests that despite recommendations from NICE (National Institute for Health and Clinical Excellence 2010b) and Public Health England (Public Health England 2014), the use of IPCs has not increased. More concerning, the same survey found $80 \%$ of Health Authorities had an organised injury prevention alliance (Watson and White 2001), whilst our survey found only 50\% of LAs/HBs had such an alliance. One of the key aims of the Health and Social Care Act 2012 was to allow the wider determinants of health to be tackled more effectively by facilitating partnership working. Our findings suggest this has not been realised with respect to child home injury prevention.

The lack of strategic approach to child home injury prevention found here mirrors the findings of a national survey of Primary Care Groups and Trusts in 2003, which found most respondents did not have a written injury prevention strategy. Recent national surveys of child injury prevention activity in Children's Centres in England report a higher prevalence of child injury prevention strategies (47\% in 2010 (Watson et al. 2014) and 42\% in 2012 (Watson et al. 2016)), suggesting greater strategic development than we found. The development of a strategy is often seen as a "starting" point for public health activity, including injury prevention. However, it can be the case that although strategies may be developed, the recommendations identified in the strategy are not always actioned. Our results would support this, as LA/HBs with child injury prevention strategies were not more likely to undertake a range of other child injury prevention activities. LA/HBs may therefore require support to implement the child injury prevention strategies they develop. 
The two Children's Centre surveys also reported on the prevalence of home safety equipment schemes in their localities; 64\% reported schemes in 2010 (Watson et al. 2014) and 42\% in 2012 (Watson et al. 2016). The reduction in home safety equipment schemes was attributed to the cessation of the English National Safe at Home safety equipment scheme, when government funding was withdrawn in 2011. Our findings suggest, despite recommendations about providing home safety assessment and equipment schemes in NICE guidance (National Institute for Health and Clinical Excellence 2010a, 2010b) and Public Health England guidance (Public Health England 2014), the prevalence of schemes still has not returned to the level in 2010.

\section{Conclusion}

Recent national guidance on preventing home injuries in childhood is being used by LAs/HBs to inform decisions about commissioning or providing child home injury prevention activities. However, this has yet to have a major impact on strategy development, partnership working, co-ordination of injury prevention activity or on commissioning or provision of evidence-based activity in most LAs/HBs There is considerable scope for LAs, in particular, to take advantage of opportunities for child injury prevention provided by the Health and Social Care Act. Achieving this in the face of continued budget cuts will be challenging, and highly effective partnership working is likely to be required. Local authorities and health boards are likely to require more support to develop their child injury prevention capability.

Acknowledgements Ethical approval was obtained from the Division of Epidemiology and Public Health Ethics Committee, University of Nottingham (Level A1 - approved on $18 / 05 / 15)$. The authors are indebted to the public health staff who took the time to complete this survey.

Funding This study was funded by The Department of Epidemiology and Public Health, University of Nottingham

\section{Competing interests None}

Provenance and peer review Not commissioned, externally peer reviewed 



\section{REFERENCES}

British Medical Association. 2001. Injury Prevention. London: BMA.

Children in Wales. 2008. Working towards a child safety strategy for Wales. Cardiff: Children in Wales.

Department of Health. 2012. Health and Social Care Act 2012, c.7. 2012. Available from: http://www.legislation.gov.uk/ukpga/2012/7/contents/enacted. London: DOH.

Edwards, P., I. Roberts, J. Green, and S. Lutchmun. 2006. "Deaths from injury in children and employment status in family: analysis and trends in class specific death rates." British Medical Journal 313:784-6.

Edwards, P., I. Roberts, M. Clarke, C. DiGuiseppi, S. Pratap, R. Wentz, and I. Kwan. 2002. "Increasing response rates to postal questionnaires: systematic review." British Medical Journal 324 (7347):1183-90.

Edwards, P., I. Roberts, M. Clarke, C. DiGuiseppi, R. Wentz, I. Kwan, R. Cooper, M. Felix, and S. Pratap. 2009. "Methods to increase response to postal and electronic questionnaires." Cochrane Database of Systematic Reviews (3). doi: 10.1002/14651858.MR000008.pub4.

Hemenway, D. 2009. While We Were Sleeping. Success Stories in Injury and Violence, Berkeley: University of California Press.

Hippisley-Cox, J., L. Groom, D. Kendrick, C. Coupland, E. Webber, and B. Savelyich. 2002. "Cross sectional survey of socioeconomic variations in severity and mechanism of childhood injuries in Trent 1992-7." British Medical Journal 324 (7346):1132. doi: 10.1136/bmj.324.7346.1132.

Hogg, C. 1996. Preventing children's accidents a guide for health authorities and boards. London: Child Accident Prevention Trust.

Kendrick, D., B. Young, A. Mason-Jones, N. Ilyas, F. Achana, N Cooper, S. Hubbard, A. Sutton, S Smith, P. Wynn, C Mulvaney, M. Watson, C. Coupland. 2012. "Home safety education and provision of safety equipment for injury prevention." Cochrane Database of Systematic Reviews 2012, Issue 9. Art. No.: CD005014.

Laflamme, L., S. Burrows and M Hasselberg. 2009. Socioeconomic differences in injury risks. A review of findings and a discussion of potential countermeasures. Copenhagen: WHO Regional Office for Europe.

Lyons, R., S. Jones, T. Deacon, and M. Heaven. 2003. "Socioeconomic variation in injury in children and older people: a population based study." Injury Prevention 9 (1):33-7.

McColl, E., A. Jacoby, L. Thomas, J. Soutter, C. Bamford, N. Steen, R. Thomas, E. Harvey, A. Garrat, and J. Bond. 2001. "Design and use of questionnaires: a review of best practice applicable to surveys of health service staff and patients." Health Technology Assessment $5(31)$.

National Institute for Health and Clinical Excellence. 2010a. Preventing unintentional injuries in the home among children and young people aged under 15: home safety assessments and providing safety equipment. NICE public health guidance 30. London: NICE.

National Institute for Health and Clinical Excellence. 2010b. Strategies to preventing unintentional injuries in under 15s. NICE public health guidance 29. London: NICE.

National Institute for Health and Clinical Excellence. 2013. Strategies to prevent unintentional injuries among children and young people aged under 15: Evidence Update February 2013. London: NICE.

Peden, M., K. Oyebite, J. Ozanne-Smith, A. Hyder, C. Branche, F. Rahman, F. Rivara , and K. Bartolomeos. 2008. World Report on Child Injury Prevention. Geneva: WHO.

Public Health England. 2012. Children (under 18, under 5, 5-17) hospital admissions due to injury, 2010-2011. London: Public Health England. 
Public Health England. 2014. Reducing unintentional injuries in and around the home among children under five years. London: Public Health England.

Public Health England. "Hospital admissions caused by unintentional and deliberate injuries in children (0-4 years)." Public Health England, Accessed 18/12/2015. http://atlas.chimat.org.uk/IAS/dataviews/report?reportId=327\&viewId=454\&geoReportId $=4137 \&$ geoId $=4 \&$ geoSubsetId $=$.

Public Health England. "Index of Multiple Deprivation." Accessed 18/12/2015. http://atlas.chimat.org.uk/IAS/dataviews/report?reportId=329\&viewId=12\&geoReportId= 3376\&geoId $=2 \&$ geoSubsetId=.

Sethi, D., E. Towner, J. Vincenten, M. Segui-Gomez, F. Racioppi. 2008. European report on child injury prevention. Geneva: WHO.

StataCorp. 2013. Stata Statistical Software: Release 13. College Station, TX: StataCorp LP.

Towner, E., Y. Carter, and M. Hayes. 1998. "Implementation of injury prevention for children and young people." Injury Prevention 4 (4 Suppl):S26-S33.

Watson, M., and J. White. 2001. "Accident prevention activities: A national survey of health authorities." Health Education Journal 60 (3):275-83.

Watson, M., C. Mulvaney, D. Kendrick, J. Stewart, C. Coupland, M. Hayes and P. Wynn on behalf of the Keeping Children Safe programme team. 2014. "National survey of the injury prevention activities of children's centres." Health \& Social Care in the Community 22 (1):40-6.

Watson, M., and G. Errington, 2016. Preventing unintentional injuries in children: successful approaches. Paediatrics and Child Health. 26(5), 194-199.

Watson, M., C. Mulvaney, C. Timblin, J. Stewart, C. Coupland, T. Deave, M. Hayes, and D. Kendrick. 2016. "Missed opportunities to keep children safe? National survey of injury prevention activities of children's centres." Health Education Journal 75 (7):833-42. 
Table 1: Strategic documents that included child injury prevention

\begin{tabular}{|l|c|}
\hline Strategic documents & $\mathbf{n}(\%)$ \\
\hline $\begin{array}{l}\text { Joint strategic needs assessment } \\
(\mathrm{N}=86)\end{array}$ & $65(76 \%)$ \\
\hline Child and young people's plan (N=83) & $42(51 \%)$ \\
\hline DPH annual report ( $\mathrm{N}=82)$ & $27(33 \%)$ \\
\hline Health and well-being strategy (N=84) & $24(29 \%)$ \\
\hline $\begin{array}{l}\text { Child injury prevention strategy } \\
(\mathrm{N}=86)\end{array}$ & $16(19 \%)$ \\
\hline
\end{tabular}

Table 2: Data sources used to make decisions on child injury prevention activities.

\begin{tabular}{|l|c|}
\hline Data sources & $\mathbf{n ~ ( \% )}$ \\
\hline $\begin{array}{l}\text { Public Health Outcomes framework } \\
(\mathrm{N}=87)\end{array}$ & $69(79 \%)$ \\
\hline Hospital admissions $(\mathrm{N}=90)$ & $70(78 \%)$ \\
\hline A\&E attendance $(\mathrm{N}=87)$ & $66(76 \%)$ \\
\hline Death $(\mathrm{N}=84)$ & $54(64 \%)$ \\
\hline Cost and prevention $(\mathrm{N}=78)$ & $35(45 \%)$ \\
\hline
\end{tabular}

Table 3: Injury prevention activities of local authorities and health boards.

\begin{tabular}{|l|c|c|c|}
\hline Injury prevention activities & $\begin{array}{c}\text { Yes* } \\
\mathrm{n}(\%)\end{array}$ & $\begin{array}{c}\text { No } \\
\mathrm{n}(\%)\end{array}$ & $\begin{array}{c}\text { Don't know } \\
\mathrm{n}(\%)\end{array}$ \\
\hline $\begin{array}{l}\text { Written child injury prevention strategy } \\
(\mathrm{N}=86)\end{array}$ & $16(19 \%)$ & $62(72 \%)$ & $8(9 \%)$ \\
\hline Training (N=91) & $39(43 \%)$ & $32(35 \%)$ & $20(22 \%)$ \\
\hline Home safety assessments (N=92) & $40(43 \%)$ & $41(45 \%)$ & $11(12 \%)$ \\
\hline Equipment scheme (N=91) & $39(43 \%)$ & $38(42 \%)$ & $14(15 \%)$ \\
\hline Child injury alliance $(\mathrm{N}=88)$ & $44(50 \%)$ & $29(33 \%)$ & $15(17 \%)$ \\
\hline
\end{tabular}

* Due to the structure of public health in Wales, yes responses include those where the health board or at least one local authority within a health board took part in the injury prevention activity 


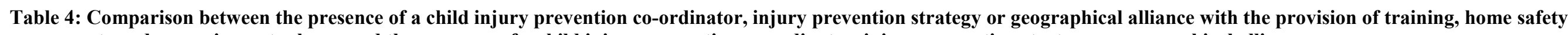
assessments and an equipment scheme and the presence of a child injury prevention co-ordinator, injury prevention strategy or geographical alliance.

\begin{tabular}{|c|c|c|c|c|c|c|c|c|c|c|c|c|c|c|c|}
\hline & \multicolumn{15}{|c|}{ Injury prevention activities } \\
\hline & \multicolumn{3}{|c|}{ Training } & \multicolumn{3}{|c|}{ Home safety assessment } & \multicolumn{3}{|c|}{$\begin{array}{c}\text { Home safety equipment } \\
\text { scheme }\end{array}$} & \multicolumn{3}{|c|}{ Injury prevention strategy } & \multicolumn{3}{|c|}{ Geographical alliance } \\
\hline & Yes & No & $\begin{array}{c}\text { OR } \\
(95 \% \mathrm{Cl})\end{array}$ & Yes & No & $\begin{array}{c}\text { OR } \\
(95 \% \mathrm{Cl})\end{array}$ & Yes & No & $\begin{array}{c}\text { OR } \\
(95 \% \mathrm{Cl})\end{array}$ & Yes & No & $\begin{array}{c}\text { OR } \\
(95 \% \mathrm{Cl})\end{array}$ & Yes & No & $\begin{array}{c}\mathrm{OR} \\
(95 \% \mathrm{Cl})\end{array}$ \\
\hline No coordinator & $\begin{array}{c}20 \\
(32 \%)\end{array}$ & $\begin{array}{c}42 \\
(68 \%)\end{array}$ & 1.00 & $\begin{array}{c}22 \\
(34 \%)\end{array}$ & $\begin{array}{c}42 \\
(66 \%)\end{array}$ & 1.00 & $\begin{array}{c}20 \\
(32 \%)\end{array}$ & $\begin{array}{c}42 \\
(68 \%)\end{array}$ & 1.00 & $\begin{array}{c}6 \\
(10 \%)\end{array}$ & $\begin{array}{c}53 \\
(90 \%)\end{array}$ & 1.00 & $\begin{array}{c}24 \\
(40 \%)\end{array}$ & $\begin{array}{c}36 \\
(60 \%)\end{array}$ & 1.00 \\
\hline Coordinator & $\begin{array}{c}19 \\
(66 \%)\end{array}$ & $\begin{array}{c}10 \\
(34 \%)\end{array}$ & $\begin{array}{c}3.99 \\
(1.57- \\
10.14) \\
\end{array}$ & $\begin{array}{c}17 \\
(61 \%)\end{array}$ & $\begin{array}{c}11 \\
(39 \%)\end{array}$ & $\begin{array}{c}2.95 \\
(1.18- \\
7.38) \\
\end{array}$ & $\begin{array}{c}20 \\
(69 \%)\end{array}$ & $\begin{array}{c}9 \\
(31 \%)\end{array}$ & $\begin{array}{c}4.67 \\
(1.80- \\
12.07) \\
\end{array}$ & $\begin{array}{c}10 \\
(37 \%)\end{array}$ & $\begin{array}{c}17 \\
(63 \%)\end{array}$ & $\begin{array}{c}5.20 \\
(1.65- \\
16.41) \\
\end{array}$ & $\begin{array}{c}20 \\
(71 \%)\end{array}$ & $\begin{array}{c}8 \\
(29 \%)\end{array}$ & $\begin{array}{c}3.75 \\
(1.42- \\
9.88) \\
\end{array}$ \\
\hline $\begin{array}{l}\text { No injury } \\
\text { prevention } \\
\text { strategy }\end{array}$ & $\begin{array}{c}27 \\
(39 \%)\end{array}$ & $\begin{array}{c}42 \\
(61 \%)\end{array}$ & 1.00 & $\begin{array}{c}29 \\
(41 \%)\end{array}$ & $\begin{array}{c}41 \\
(59 \%)\end{array}$ & 1.00 & $\begin{array}{c}28 \\
(41 \%)\end{array}$ & $\begin{array}{c}20 \\
(59 \%)\end{array}$ & 1.00 & & & & $\begin{array}{c}30 \\
(44 \%)\end{array}$ & $\begin{array}{c}38 \\
(56 \%)\end{array}$ & 1.00 \\
\hline $\begin{array}{l}\text { Injury } \\
\text { prevention } \\
\text { strategy }\end{array}$ & $\begin{array}{c}9 \\
(56 \%)\end{array}$ & $\begin{array}{c}7 \\
(44 \%)\end{array}$ & $\begin{array}{c}2.00 \\
(0.67-6.00)\end{array}$ & $\begin{array}{c}9 \\
(56 \%)\end{array}$ & $\begin{array}{c}7 \\
(44 \%)\end{array}$ & $\begin{array}{c}1.82 \\
(0.61- \\
5.44)\end{array}$ & $\begin{array}{c}10 \\
(63 \%)\end{array}$ & $\begin{array}{c}6 \\
(38 \%)\end{array}$ & $\begin{array}{c}2.38 \\
(0.78-7.31)\end{array}$ & & & & $\begin{array}{c}10 \\
(67 \%)\end{array}$ & $\begin{array}{c}5 \\
(33 \%)\end{array}$ & $\begin{array}{c}2.53 \\
(0.78- \\
8.21)\end{array}$ \\
\hline $\begin{array}{l}\text { No } \\
\text { geographical } \\
\text { alliance }\end{array}$ & $\begin{array}{c}10 \\
(23 \%)\end{array}$ & $\begin{array}{c}34 \\
(77 \%)\end{array}$ & 1.00 & $\begin{array}{c}15 \\
(34 \%)\end{array}$ & $\begin{array}{c}29 \\
(66 \%)\end{array}$ & 1.00 & $\begin{array}{c}12 \\
(28 \%)\end{array}$ & $\begin{array}{c}31 \\
(72 \%)\end{array}$ & 1.00 & & & & & & \\
\hline $\begin{array}{l}\text { Geographical } \\
\text { alliance }\end{array}$ & $\begin{array}{c}26 \\
(60 \%)\end{array}$ & $\begin{array}{c}17 \\
(40 \%)\end{array}$ & $\begin{array}{c}5.20 \\
(2.05- \\
13.22) \\
\end{array}$ & $\begin{array}{c}22 \\
(51 \%)\end{array}$ & $\begin{array}{c}21 \\
(49 \%)\end{array}$ & $\begin{array}{c}2.03 \\
(0.85- \\
4.80) \\
\end{array}$ & $\begin{array}{c}26 \\
(60 \%)\end{array}$ & $\begin{array}{c}17 \\
(40 \%)\end{array}$ & $\begin{array}{c}3.95 \\
(1.60-9.76)\end{array}$ & & & & & & \\
\hline
\end{tabular}



